\title{
Clinical Implications in Orbital and Pterional Flap Surgeries as Well as Radioimaging Studies to Determine Topographical Prevalence and Characterization of Meningo-Orbital Foramen in Orbits of the Indian Population
}

\author{
Implicaciones Clínicas en Cirugías de Colgajo Orbitario y Pterional, así como Estudios de \\ Radioimagen para Determinar la Prevalencia Topográfica y la Caracterización del Foramen \\ Meningoorbitario en Órbitas de la Población India
}

Mehandi Vinayak Mahajan'; A. Anupriya²; G.Durga Devi³ ${ }^{3}$ Nita A Tanna ${ }^{4}$;itin Radhakishan Mudiraj ${ }^{5}$ Sangeeta Das $^{6}$

MAHAJAN, M. V.; ANUPRIYA, A.; DEVI, G. D.; TANNA, N. A.; MUDIRAJ, NITIN R. \& DAS, S. Clinical implications in orbital and pterional flap surgeries as well as radioimaging studies to determine topographical prevalence and characterization of meningo-orbital foramen in orbits of the indian population. Int. J. Morphol., 38(6):1810-1817, 2020.

SUMMARY: The pear-shaped bony orbit connects with intracranial cavity via foramina's and fissures. The Meningo-orbital Foramen(MOF) is usually present in greater wing of sphenoid close to lateral edge of Superior orbital fissure. It provides a route for an anastomosis between the orbital branch of the middle meningeal artery(MMA) and recurrent meningeal branch of Ophthalmic Artery(OA) and hence, risk of damage during surgeries can occur. To verify occurrence and location, with morphology of MOF in dry orbits and the impending clinical hazards in surgeries pertaining to the orbit, document and analysis it to determine a standardized guideline. The presence for MOF was studied in 446 dry orbits with its location from the supra orbital margin (SOM), front zygomatic suture (FZS), the lateral tubercle of Whitnall (WT)and the lateral end of superior orbital fissure(SOF) along with its patency, laterality and number of foramina's present. Nylon probes, long divider/pins, compass and Vernier callipers was used to check the patency and various parameters. The study noted the percentage prevalence of MOF as $69 \%$ with communication with middle cranial fossa(MCF) being $76 \%$ of $69 \%$ and the average distance from SOM, FZS, WT and lateral end of SOF being $35.58 \mathrm{~mm}, 24.9 \mathrm{~mm}, 26.6 \mathrm{~mm}$ and $0.92 \mathrm{~mm}$. On comparison with various population studies, certain similarities and differences with regards to different parameters were noted. Prevalence of MOF was mostly unilateral and showed multiple foramina, that can act as channels for arteries, a variant of MMA or OA, that supply orbital structures or tumour growths. Thus, awareness of this variation is of prime importance to ophthalmologists and neurosurgeons as well as interventional radiologists, in preventing haemorrhagic condition which could further raise the difficulties in operative procedures and surgical outcomes.

KEY WORDS: Meningo-orbital foramen; Superior orbital fissure; Frontozygomatic suture; Whitnall tubercle; Orbit; Pterional flap.

\section{INTRODUCTION}

The foramens in the orbit along with their variants help maxillofacial surgeons or neurosurgeons, ophthalmologists and anesthetists plan their surgeries and blocks by preventing damage to nerves and vessels. Although the main orbital communications with the intracranial cavity occur through the optic canal, superior orbital fissure (SOF) and inferior orbital fissure (IOF), previous studies showed that additional communications exist through the meningoorbital foramen (MOF) and accessory foramen, which are maximally located in the greater wing of the sphenoid of the orbit, adjacent to the SOF or in the orbital wall of the frontal bone (Simão-Parreira et al., 2019). These provide routes for anastomoses between the orbital branch of the middle meningeal artery (MMA) and recurrent meningeal branch of the ophthalmic artery (OA) or the lacrimal branch of OA (Kwiatkowski et al., 2003; Celik et al., 2014). Thus, during resection of meningiomas or any orbital surgeries, this communication is hazardous and can cause hemorrhage,

\footnotetext{
${ }^{1}$ Associate Professor.Sri Muthukumaran Medical College, Hospital And Research Institute.The Tamil Nadu Dr. M.G.R Medical University, Chennai, India. ${ }^{2}$ Assistant Professor. Sri Ramachandra Medical College And Research Institute. Sri Ramachandra Institute Of Higher Education, India.

${ }^{3}$ Associate Professor. Sree Balaji Medical College And Hospital,Chennai, India.

${ }^{4}$ Associate Professor.Gmers Medical College, Gotri, Baroda, India.

${ }^{5}$ Professor,Hod.Bharati Vidyapeeth University, Medical College And Hospital, Sangli, India.

${ }^{6}$ Professor,Hod. Malla Reddy Institute Of Medical Sciences, Hyderabad, Kaloji Narayanrao University Of Health Sciences, Telangana, India
} 
MAHAJAN, M. V.; ANUPRIYA, A.; DEVI, G. D.; TANNA, N. A.; MUDIRAJ, NITIN R. \& DAS, S. Clinical implications in orbital and pterional flap surgeries as well as radioimaging studies to determine topographical prevalence and characterization of meningo-orbital foramen in orbits of the indian population. Int. J. Morphol., 38(6):1810-1817, 2020.

thereby further aggravating difficulties in dissection. The MOF also acts as a conduit between the middle/anterior cranial fossa and the orbit (Georgiou \& Cassell, 1992; O'Brien \& McDonald, 2007). The MOF presence is not constant, and it occupies a somewhat variable position relative to SOF. That is, the MOF lies either lateral to it, confluent with the lateral end of the fissure or occupying any intermediate position between these extremes. The MOF may be single or multiple, and it may be present unilaterally or bilaterally (Georgiou \& Cassell; Kwiatkowski et al.).

Studies by various authors have reported various prevalences. It can be in the range from $6 \%$ to $82.5 \%$ (Mysorekar \& Nandedkar, 1987; Georgiou \& Cassell; McQueen et al., 1995; Erturk et al., 2005). The abnormal origin of the MMA, the lacrimal artery (LA) and OA may lead to communication between the anterior or middle cranial fossa (MCF) and orbit through this foramen. Thus, the presence of MOF should be realized during reconstruction of the anterior base of the skull or orbital base surgery or meningioma excision (Erturk et al.).

The acknowledgment of this foramen and related structures passing through it should be recognized by ophthalmologists, neurosurgeons as well as diagnostic medical imaging teams and radiologists due to their surgical significance. Therefore, with this criterion, the aim of the present study was to explore dry orbits for the presence of MOF and standardized anatomical landmarks with regard to its distance from certain fixed bony points, to check its patency with the intracranial cavities, and to understand its numbers with laterality in the Indian population. This will help surgeons navigate the precise location of MOF and facilitate orbital or neurological surgical procedures such as pterional flap or any interventional radio imaging techniques without any hazards.

Table I. Values of different parameters in present study.

Meningo-orbital foramina (MOF) of 446 orbits
\%of presence of MOF
$\%$ of single MOF
$\%$ of multiple MOF
$\%$ of unilaterally present MOF
$\%$ of bilaterally present MOF
$\%$ of patent communicating with intracranial cavity
$\%$ of non-communicating with intracranial cavity
Average diameter of MOF
Average Distance between MOF and lateral angle of SOF
Average Distance between MOF and FZS with SD
Average Distance between MOF and SOM with SD
Average Distance between MOF and lateral orbital WT with

\section{MATERIAL AND METHOD}

A total of 446 orbits from 223 dry skulls were studied from the Departments of Anatomy at Medical Colleges in Chennai, Hyderabad, Mumbai and Sangli. The prevalence of MOFs was studied with regard to their presence along with their numbers and laterality. The patency of the foramen was ascertained using a fine nylon probe/long pin and observing its communication with the cranial cavity. The distance between MOF and the supraorbital margin (SOM), the fronto-zygomatic suture (FZS), the lateral tubercle of Whitnall (WT) and the lateral angle of SOF were measured using a divider/compass, and the units were measured using a digital Vernier caliper. Damaged orbits were excluded from the study, and the data were analyzed using descriptive statistics. The data obtained on the various parameters were compared and discussed with different population studies, including the Korean, Polish, Turkish, Scottish, Americans, Serbian, Chilean, Italian, Japanese, Portuguese, Thai, Brazilian and Indian populations, wherever applicable.

\section{RESULTS}

The results are expressed in Tables I and II and Figs.

1-4.

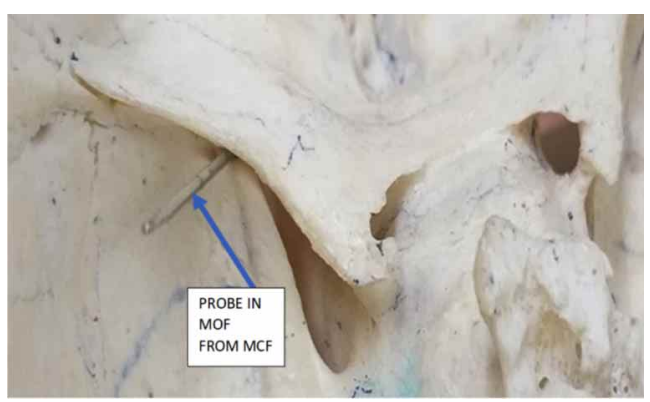

Fig. 1. Patency of left sided mof from middle cranial fossa[MCF]

Value
$69.05 \%$ (308 orbits)
$43.04 \%$ (192 orbits)
$26 \%$ (116 orbits)
$53.37 \%$ of 223 skulls $(119$ skulls $)$
$46.63 \%$ of 223 skulls (104 skulls)
$76.94 \%$ of 308 orbits with middle fossa $(237$ orbits $) ; 4.22 \%$ of 308
orbits with anterior fossa; $(13$ orbits $)$ Overall $-53.13 \%$ of 446 orbits
$18.83 \%$ of 308 orbits with middle fossa $(58$ orbits $)$ Ov erall- $13 \%$ of
446 rhits
$0.92 \mathrm{~mm}($ range $=0.5-1.7 \mathrm{~mm})$
$6.7 \mathrm{~mm} ;($ range $=4.2-9.4 \mathrm{~mm})$
$24.9 \mathrm{~mm}(+/-3.4)$ Range $=17.2-34.4 \mathrm{~mm}$
$35.58 \mathrm{~mm}(+/-3.8)$ Range $=25.7-43.2 \mathrm{~mm}$
$26.6 \mathrm{~mm}(+/-3.6)$ Range $=19.7-33.1 \mathrm{~mm}$




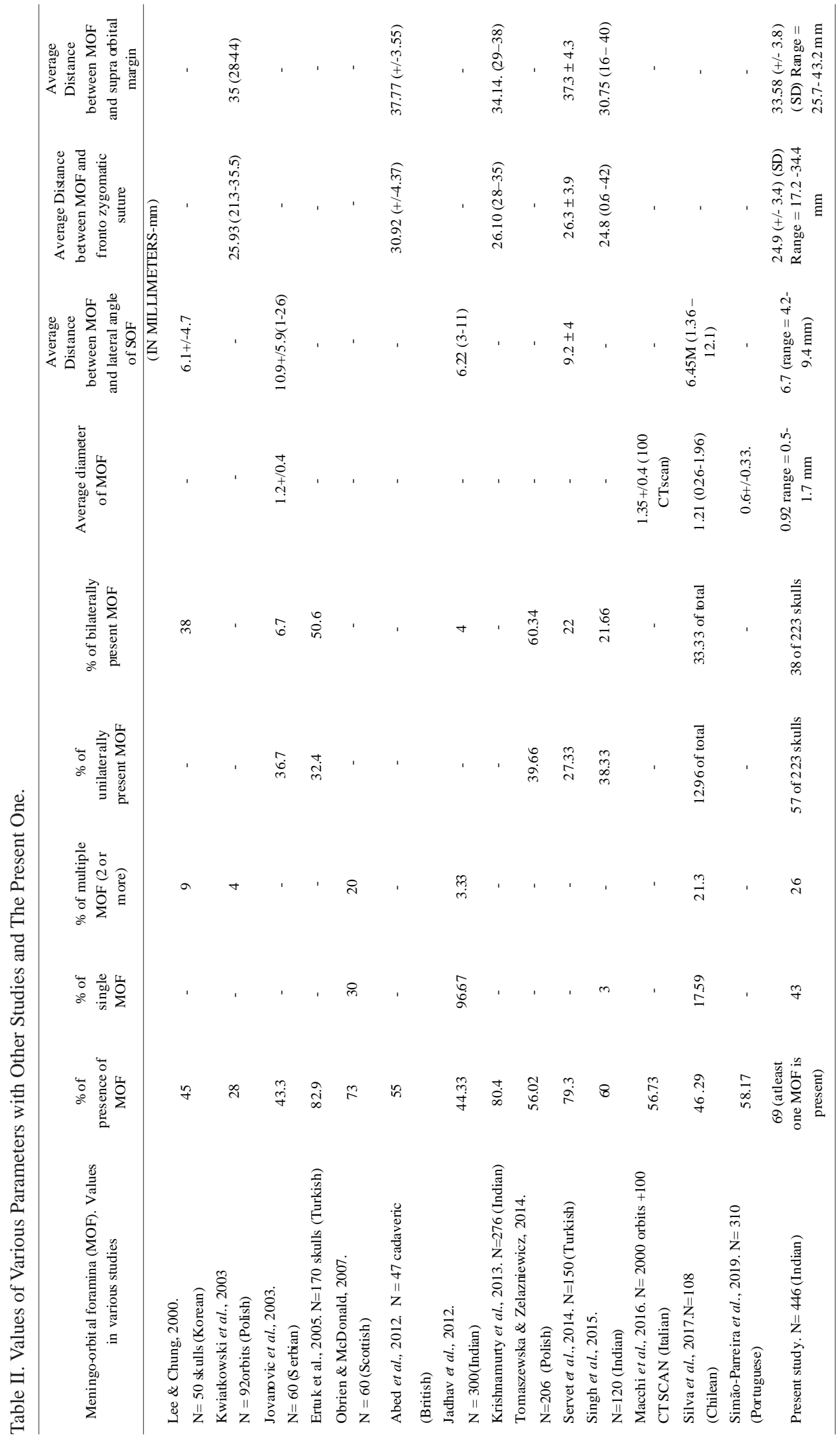

DISCUSSION

The meningoorbital foramen (MOF) is also known as the ophthalmo-meningeal foramen, lacrimal foramen, meningeal foramen, sphenofrontal foramen, cranio-orbital foramen, and stapedial-ophthalmo-lacrimal foramen (Georgiou \& Cassell; Shimada et al., 1995; Jovanovic et al., 2003). It is an anatomical variant that is usually located in the lateral wall of the orbit, composed of zygomatic bone and the greater wing of the sphenoid. The important landmarks in the wall are FZS and the lateral orbital WT, which is a small elevation in the lateral wall and is located $11 \mathrm{~mm}$ above the FZS and $5 \mathrm{~mm}$ behind the orbital margin (Celik et al.). This wall is located adjacent to the middle cranial and temporal fossa and shows the presence of MOF most of the time.

Erturk et al. mentioned many foramina present in the frontal bone. The MOF communicates with the middle and anterior cranial fossa. The present study showed a prevalence of MOF in $69.05 \%$ of 446 orbits (unilateral $43.04 \%$ and bilateral $26 \%$ ) (Table I). It is known to range from $6 \%$ in 100 orbits to 82.9 $\%$ in 340 orbits (8-9). Even from Table II, it is noted that, in comparison across various population 


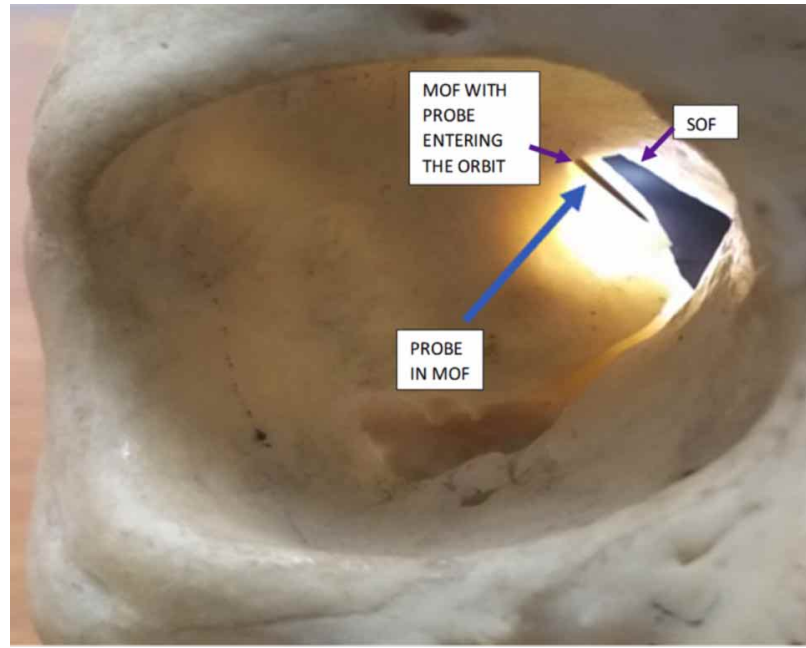

Fig. 2. Patency and presence of mof in left orbit.

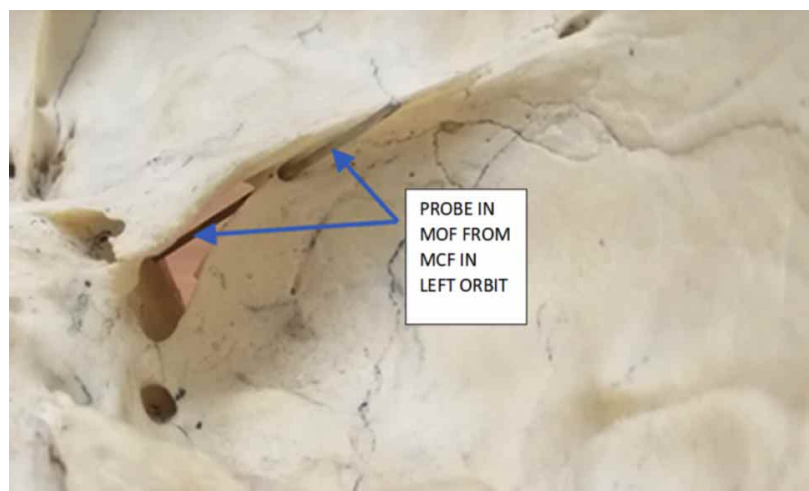

Fig. 3. Patency of mof from middle cranial fossa into the right sided orbit

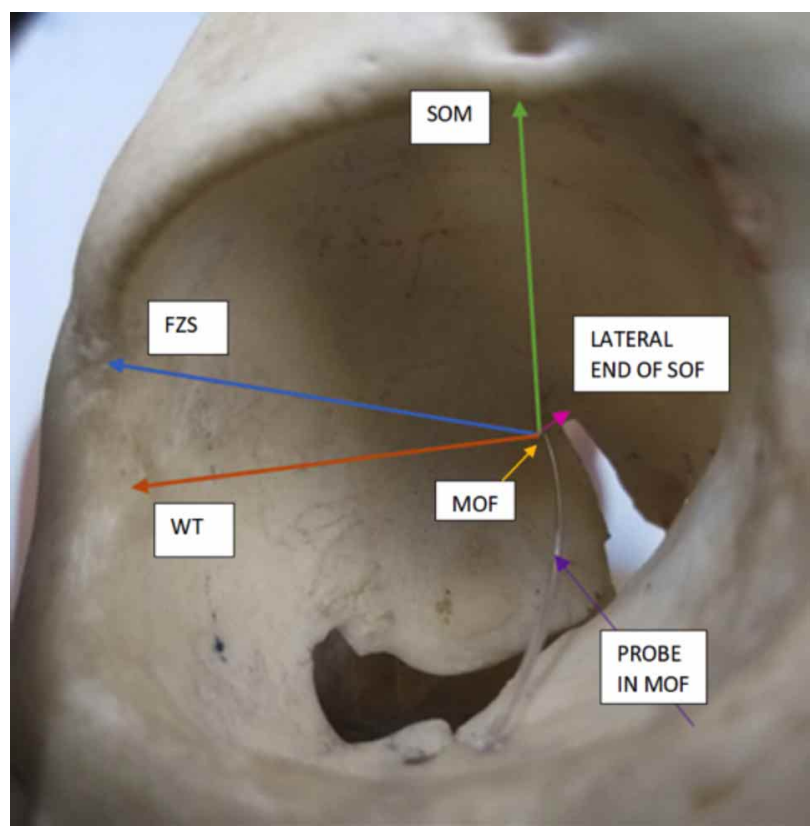

Fig. 4. Arrows showing anatomical points from mof to supra orbital margin (SOM), frontozygomatic suture (FZS), whitnall tubercle (WT) and superior orbital foramen (SOF). studies, the prevalence of MOF ranges from 28-82.9\%. Indian studies by Jadhav et al. (2012), Krishnamurthy et al. (2008), and Singh et al. (2015) with comparison to the current study also showed vast differences from 44 to $81 \%$ : In Georgia and Cassell (1992), an American study - $50 \%$; Mysoerkar et al. (1987) an Indian study - $76 \%$; and Shimada et al., a Japanese study $-45 \%$. These were population studies that showed that MOF prevalence was very prominent. Based on the number of foramens present, single MOFs were more than multiple ones, and the present study noted these were 43.04 $\%$ and $26 \%$, respectively. In comparison with different populations, a wide range of single ones were from 0.5 to $96.67 \%$ single, though O'Brien \& McDonald a Scottish study, and the current study were in similar ranges (Table II). O'Brien \& McDonald a Scottish study, Silva et al. (2017), a Chilean study, and the current study showed similar ranges of 20-26 $\%$ with regards to multiple foramens, while in studies of Kwiatkowski et al. (Polish), Lee \& Chung (2000) (Korean), and Jadhav et al. (Indian) noted much lower percentages of multiple foramens (0.5-9 \%) (Table II). Thus, multiple foramens are present, and the percentages may vary. These MOFs can have feeder arteries or communicating arteries passing through them; therefore, when cauterizing feeder vessels, care must be taken to look for all such variations.

In comparing the laterality, a high percentage of bilateralism of MOF was mentioned in studies by Erturk et al. (Turkish); Lee \& Chung (Korean), Silva et al. (Chilean), and Tomaszewska \& Zelazniewicz (2014) (Polish) and the current study, with the range being 33-60\%, followed by Celik et al. (Turkish) and Singh et al. (Indian) in the range of 21-22\%, while the least ranged from 4-8 \% in Jadhav et al. (Indian) and Jovanovic et al. (Serbian). A higher percentage of unilateral MOF was observed in the current study (57\%), followed by the Erturk et al., Jovanovic et al. (Serbian), Celik et al. (Turkish) and Tomaszewska \& Zelazniewicz (Polish) studies, the range of which was 27-38\%, with the least of 12 $\%$ in Silva et al. (Chilean) (Table II). Thus, the presence of MOF, whether single or multiple, whether unilateral or bilateral, cannot be denied, and it becomes imperative to be cautious during deep orbital dissection surgeries or pterional flap surgeries (PFS) as communicating arteries might be present. The longest diameter of MOF usually varies from 0.3 to $4 \mathrm{~mm}$ (Nabili et al., 2006). This value in the current study was $0.92 \mathrm{~mm}$ (Table I), and a similar range was noted in various studies. The MOF, if present, acts as a channel for variants of vascular anastomosis between the MMA and LA or recurrent meningeal branch from the $\mathrm{OA}$, a communication between the external carotid artery (ECA) and internal carotid artery (ICA), where these variants can occur if the development of the foramen spinosum has not taken place. In some cases, this anastomosis may replace the OA as the primary blood supply to the orbit (Krishnamurty et al., 2008). 
MAHAJAN, M. V.; ANUPRIYA, A.; DEVI, G. D.; TANNA, N. A.; MUDIRAJ, NITIN R. \& DAS, S. Clinical implications in orbital and pterional flap surgeries as well as radioimaging studies to determine topographical prevalence and characterization of meningo-orbital foramen in orbits of the indian population. Int. J. Morphol., 38(6):1810-1817, 2020.

Therefore, with this large variation in the dimension of MOF, large caliber arteries can pass through it. Surgeons need to keep in mind that the presence of such an artery, if not appropriately approached, can lead to a huge loss of blood and can lead to total blindness in those patients if that variant artery is the sole supply to orbit. Additionally, the presence of MOF could also be mimicked as a foreign body on a CT scan, showing it as a radiopaque area with central radiolucency in cases of intraocular foreign body (IOFB) injuries, which can lead to further confusion (Nabili et al.). Thus, the confirmation of MOF in these cases is to note if that radiopaque area is stationary even with change of head positions as an IOFB would move.

Georgiou \& Cassell demonstrated communication between the orbit and MCF through MOF with a $0.1 \mathrm{~mm}$ flexible probe. Thus, with the help of a fine nylon probe/pin, the patency \% of MOF communicating with MCF was noted in the present study to be $76.94 \%$ (Table I; Figs. 1 to 3 ) as against studies by Jadhav et al. that showed being $100 \%$ and $46.66 \%$ in Obrien \& McDonald, while $4 \%$ of the current study was communicating with ACF (Table I), which is concurring with O'Brien \& McDonald. Noncommunicating MOFs were also present, as seen in Table II. Mysorekar \& Nandedkar study also showed the presence of a groove for the orbital branch of the MMA, and it also mentioned that MMA might have been replaced by a recurrent branch of the LA where the foramen spinosum was absent, as seen in 2 cases. Additionally, communications were present with ACF, as in Obrien \& McDonald; however, as the vessels were difficult to observe due to the presence of the lesser wing of the sphenoid bone overhanging the groove for the orbital branch, giving rise to speculation that there was a different identity made from those that would be communicating through an opening in the lateral orbital wall. Thus, before any surgery involving deep dissection of the orbit or space-occupying lesions in the ACF or MCF where reflection of the PF (fronto-temporosphenoidal) approach to gain access to anterior skull base access is performed, the surgeon needs to go through the lateral aspect of the frontal and temporal bones, the greater wing of the sphenoid is removed, and drilling is performed in the sphenoid bone (McDermott et al., 1990). Hence, for better safety precaution, performing radioimaging studies will guide the process, and proper anatomical understanding could prevent catastrophe as the percentage of MOF existing is high and so would be the communications. Severe traction of the bony PF could lead to traction of vessels, thereby leading to hemorrhage. Additionally, the presence of MOF could have vessels traversing through them, which could be supplying the periorbital region, and communications with the roof could also act as feeder vessels for meningiomas, schwannomas, and hemangiomas, which could be of grave concern for neurosurgeons (Shimada et al.; O'Brien \& McDonald).
These anastomoses between the OA and the ECA could represent an anatomic resource or a hazard. They may provide alternative routes for the blood supply of the orbit but also an undesirable passage of embolic material during ECA embolization. Thus, facts of their anatomy and frequency in adults are required for the proper evaluation of the risk in some endovascular procedures. Varying degrees of variability with orbital hemodynamic changes of orbital blood supply with ECA dominance are noted in children when communication between OA and ECA occurs (Gailloud et al., 2009). Another study using superselective angiography showed that the optic apparatus received vascular supply from OA, a branch from MMA confirming variations in the orbital branching of $\mathrm{OA}$ and anastomosis with the ECA and ICA. Such vessels could feed meningiomas or dural arteriovenous fistulas or even cause central arterial occlusion and be target vessels for intra-arterial thrombolysis (Gailloud et al.). Thus, with great vigilance, transarterial embolization must be attempted because it is a high-risk vessel. Interventional radiologists should be warned to have proper planned endovascular therapy in case of MOF findings of vessels and connections. Serious catastrophic outcomes occur from medial and inferior wall decompression of the orbit due to its proximity to important nerves and vessels as well as due to weak integrity of the wall. A potentially safe, strong walled and effective site for orbital surgeons is the lateral wall (Baldeschi et al., 2005). Along with visual disturbances, diplopia, enophthalmos, ptosis, emphysema, and unexpected hemorrhage are also postoperative complications arising from damage or rupture of the anastomotic artery in the MOF (Baldeschi et al.). To avoid disaster, as seen in previous studies, important landmarks such as the FZS and WT are located on this wall and for a better navigational approach of MOF. To prevent damage to the contents passing through it, their distances are measured from MOF in the current study along with the distance from SOM/notch and lateral end of SOF, so the approach into the orbit can be better planned with minimal adversity (Table I; Fig. 4).

From Table II, it is observed that the distance between the FZS and MOF is in the range of $0.6-42 \mathrm{~mm}$. A Thai population study by Huanmanop et al. (2007) on 100 orbits noted the distance to be $27.2 \mathrm{~mm}$, which is similar to that of Kwiatkowski et al. (25.3 mm), Krishnamurthy et al. (26.1 $\mathrm{mm})$, Celik et al. $(26.3 \mathrm{~mm})$, Singh et al. $(24.8 \mathrm{~mm})$ and the current study with a value of $24.9 \mathrm{~mm}$, while Abed et al. (2012) (British) reported it was $30.92 \mathrm{~mm}$, which is a higher deviation. Singh et al. showed a starting range from $0.6 \mathrm{~mm}$ between FZS and MOF, which is extremely rare. A comparison of the distance between the SOM/notch and MOF ranged from 16 to $44 \mathrm{~mm}$ (Table II), and Huanmanop et al. (Thai) showed that the distance was $33.6 \mathrm{~mm}$. Abed $e t$ 
MAHAJAN, M. V.; ANUPRIYA, A.; DEVI, G. D.; TANNA, N. A.; MUDIRAJ, NITIN R. \& DAS, S. Clinical implications in orbital and pterional flap surgeries as well as radioimaging studies to determine topographical prevalence and characterization of meningo-orbital foramen in orbits of the indian population. Int. J. Morphol., 38(6):1810-1817, 2020.

al. $(37.77 \mathrm{~mm})$ and Celik et al. $(37.3 \mathrm{~mm})$ were in similar ranges to each other, while Kwiatkowski et al. (35 mm), Krishnamurthy et al. (34.14 $\mathrm{mm})$ and the current study with 33.58 were in similar ranges. Singh et al. had the smallest range of $30.7 \mathrm{~mm}$ (Table II). Using the frontal temporalorbito-zygomatic approach (FTOZ), which is an extension of PFS, masses such as meningiomas, fibrous dysplasia, hemangiomas, schwannomas and gliomas or traumatic injuries involving the skull base are approached. This is where the neurosurgeon provides orbital access for oculofacial surgeons to remove the lateral wall. The FTOZ approach provides access to intracranial optic canal decompression (McDermot et al., 1990). For reconstruction of the orbit, cranial bone graft remains the material of choice because it is autogenous tissue and the survival rate is high. Thus, in all these surgeries, encountering the MOF with its contents is very likely, and a prior diagnostic work-up using imaging techniques would help to observe a variant of OA or MMA, which could be the only source of vascular supply to the orbit or even the retina.

Celik et al. mentioned that operating $20 \mathrm{~mm}$ beyond FZS and $28 \mathrm{~mm}$ beyond SOM/notch, which are used as navigational waypoints, amplifies the risk of encountering an MOF with its contents, and during operative sessions, homeostasis should be achieved by preserving or cauterizing the vessels present. McQenns et al. (1995) defined a safe operating procedure by subtracting $5 \mathrm{~mm}$ from the shortest recorded measurement between the two landmarks, namely, FZS and SOM/notch. Thus, by studying the various distances, a safe zone area can be established, which was a part of the process from this study, and comparison with other studies has shown that the chances of finding MOFs are very high beyond that safe zone. Thus, in the current study, there are very high chances of encountering an MOF according to Celik et al. as the distances are greater and the safe operating navigation zone would be up to $15 \mathrm{~mm}$ from the FZS and up to $24 \mathrm{~mm}$ from the SOM, according to McQueen et al.

Another important landmark is the WT, and the distance between WT and MOF was seen to be $29.69+/$ $3.89 \mathrm{~mm}$ in Abed et al. (British) and $27.1+/-3.7 \mathrm{~mm}$ in Celik et al. (Turkish), while in the current study, it was 26.6 $+/-3.6 \mathrm{~mm}$; thus, the range between WT and MOF was from 19.7 to $33.1 \mathrm{~mm}$. As WT is a bony tubercle and has many important attachments to it, it is easily palpable for the surgeon or visible on radioimaging scan, thereby giving an idea at what distance a MOF can be encountered. Although multiple foramina can be present, the distance between the lateral end of the SOF and the MOF was found to be in the range of 1-26 mm (Table II). Studies from Lee \& Chung (Korean) reported $6.1 \mathrm{~mm}$, Silva et al. (Chilean) reported
$6.45 \mathrm{~mm}$, Jadhav et al. reported a value of $6.22 \mathrm{~mm}$ and in current one it was $6.7 \mathrm{~mm}$. Thus, they were in a similar range with each other; however Jovanovic et al. (Serbian) reported $10.9 \mathrm{~mm}$ and Celik et al. (Turkish) reported $9.2 \mathrm{~mm}$, which was a higher deviation from that of the current study (Table II). However, MOF was always found near the suture line of the greater wing of the sphenoid bone leading towards the SOF in the study. In the current study, few orbits showed the SOF projecting laterally, giving an impression of an incomplete foramen, which was also noted by Georgiou \& Cassell. Thus, MOF parameters that were studied in the current work can have an impact on its prevalence due to varying age groups, gender, ethnic groups and geographical residence. Its occurrence can be congenital or acquired and could result in various diseases, such as osteopetrosis, osteoporosis, Curzon's syndrome, neurofibromatosis, brachymicrocephaly and mental retardation (Singh et al.).

Depending on the development of the embryological vascular supply of the orbit, anatomical studies indicate the formation of MOF and its contents (Celik et al.). The orbital branch initially develops from the ICA, followed by supraorbital division of the stapedial artery. A fine vascular network around the optic nerve develops that communicates between the OA and the supraorbital branch of the stapedial artery (SA), later represented in adulthood by the MMA. It is presumed that MOF represents the point where the supraorbital division of the SA enters the orbitthrough the greater wing of the sphenoid that has not ossified yet (7). The meningo-ophthalmic artery (MOA) stands to be an important anastomosis with the anterior branch of the MMA that connects the ICA and ECA (Erdogmus \& Govsa, 2005). Therefore, a higher prevalence of MOF means a high chance of encountering an MOA. Erdogmus \& Govsa reported MOA in $31.6 \%$ on the right side and $26.3 \%$ on the left side. The study mentioned that the recurrent meningeal branch of the LA entered the MCF by crossing the SOF and MOF. Louw et al. (2014) was a case report of bilateral nasopharyngeal neurofibroma with epistaxis; a rare left MAO was the sole path of supply to the eye. Thus, here, embolization of feeder vessels would be unsafe with a high risk of visual blindness, which should be known to surgeons, and with proper anatomical knowledge, the sphenopalatine arteries could undergo embolization to control epistaxis. A very extremely rare variant of $\mathrm{OA}$ arising from the accessory meningeal artery was also reported by McDermott et al. Based on 1643 angiographies, an anomalous site of origin of the OA from the ICA holds a 50-fold higher risk of ICA anterior wall aneurysms, and ligation or embolization of the MMA can endanger the eye if the OA stems from the MMA; there is also a severe bleeding risk involving the lateral wall of the orbital surgeries when an OA arising from the MMA or a large MOA runs through the MOF (Macchi et al., 2016). 
MAHAJAN, M. V.; ANUPRIYA, A.; DEVI, G. D.; TANNA, N. A.; MUDIRAJ, NITIN R. \& DAS, S. Clinical implications in orbital and pterional flap surgeries as well as radioimaging studies to determine topographical prevalence and characterization of meningo-orbital foramen in orbits of the indian population. Int. J. Morphol., 38(6):1810-1817, 2020.

For these reasons, MRI angiography is imperative before undergoing any chemoembolization in cases of suspected middle cerebral artery aneurysms. As positional alterations of MOF are noted in various studies along with the current one, it is mostly correlated with the development of OA, though undermining its embryological importance of foramen, so the term "stapedial-ophthalmo-lacrimal" foramen could be proposed to proclaim its embryonic significance which Georgia et al. (1992) mentions as well.

Thus, anatomical knowledge of the MOF is of clinical significance for surgeons operating for reconstruction of the anterior base of the skull using pterional flap surgeries, orbital surgeries or interventional selective angiographies. Ophthalmologists must be aware of the presence of the MOF to avoid injury to the vessel passing through this foramen and its complications during lateral wall orbital surgeries. It is helpful for neurosurgeons operating on the basis of anterior or MCF to avoid vascular complications. The present study is an attempt to provide information regarding the topographical presence of MOF along with its characterization to help navigate a better zone area of safety due to interventional procedures.

\section{CONCLUSIONS}

Injuries to the MOA passing through the MOF during orbital operations increase the operative risks and prolong the surgical outcomes for structures at the orbital apex. Proper analysis of MOF dimensions and morphology along with their distances between their orbital opening and the selected topographical points can be of significance for clinical applications. To achieve a remarkably successful surgical outcome with shorter time and complications, the surgeon's awareness of the anatomical landmarks of the MOF can help. We also hope that, for those with keen scientific interest in the osteology and blood supply of the orbit, this study will provide guidance.

MAHAJAN, M. V.; ANUPRIYA, A.; DEVI, G. D.; TANNA, N. A.; MUDIRAJ, NITIN R. \& DAS, S. Implicaciones clínicas en cirugías de colgajo orbitario y pterional, así como estudios de radioimagen para determinar la prevalencia topográfica y la caracterización del foramen meningoorbitario en órbitas de la población india. Int. J. Morphol., 38(6):1810-1817, 2020.

RESUMEN: La órbita ósea en forma de pera se conecta con la cavidad intracraneal a través de forámenes y fisuras. El foramen meningoorbitario (MOF) suele estar presente en el ala mayor del esfenoides cerca del margen lateral de la fisura orbitaria superior. Proporciona una ruta para una anastomosis entre la rama orbitaria de la arteria meníngea media (MMA) y la rama meníngea recurrente de la arteria oftálmica (OA) y, por lo tanto, puede ocurrir riesgo de daño durante las cirugías. Para verificar la ocurrencia y ubicación, con la morfología de MOF en órbitas secas y los peligros clínicos inminentes en cirugías de la órbita, documentarlo y analizarlo para determinar una pauta estandarizada. Se estudió la presencia de MOF en 446 órbitas secas desde el margen supraorbitario (MOS), sutura cigomática frontal (FZS), el tubérculo lateral de Whitnall (WT) y el extremo lateral de la fisura orbitaria superior (SOF) junto con su permeabilidad, lateralidad y número de forámenes presentes. Se utilizaron sondas de nailon, divisores / pasadores largos, brújula y calibradores Vernier para comprobar la permeabilidad. En el estudio se pudo observar que la prevalencia porcentual de MOF era del $69 \%$, siendo la comunicación con la fosa craneal media (MCF) del $76 \%$ del $69 \%$ y la distancia promedio desde SOM, FZS, WT y el extremo lateral de SOF era de $35,58 \mathrm{~mm}, 24,9 \mathrm{~mm}, 26,6 \mathrm{~mm}$ y $0,92 \mathrm{~mm}$. En comparación con varios estudios de población, se observaron ciertas similitudes y diferencias con respecto a diferentes parámetros. La prevalencia de MOF fue mayoritariamente unilateral y mostró múltiples forámenes, que pueden actuar como canales para las arterias, una variante de MMA u OA, que irrigan estructuras orbitarias o crecimientos tumorales. Por lo tanto, la conciencia de esta variación es de primordial importancia para los oftalmólogos y neurocirujanos, así como para los radiólogos intervencionistas, en la prevención de una enfermedad hemorrágica que podría aumentar aún más las dificultades en los procedimientos y los resultados quirúrgicos.

PALABRAS CLAVE: Foramen meningo-orbitario; Fisura orbitaria superior; Sutura frontocigomática; Tubérculo de Whitnall; Órbita; Colgajo pterional.

\section{REFERENCES}

Abed, S. F.; Shams, P.; Shen, S.; Adds, P. J.; Uddin, J. M. \& Manisali, M. A cadaveric study of the cranio-orbital foramen and its significance in orbital surgery. Plast. Reconstr. Surg., 129(2):307e-311e, 2012.

Baldeschi, L.; MacAndie, K.; Hintschich, C.; Wakelkamp, I. M. M. J.; Prummel, M. F. \& Wiersinga, W. M. The removal of the deep lateral wall in orbital decompression: its contribution to exophthalmos reduction and influence on consecutive diplopia. Am. J. Ophthalmol., 140(4):642-7, 2005

Celik, S.; Kazak, Z.; Ozer, M. A. \& Govsa F. Navigational area of the cranio-orbital foramen and its significance in orbital surgery. Surg. Radiol. Anat., 36(10):981-8, 2014.

Erdogmus, S. \& Govsa, F. Importance of the anatomic features of the lacrimal artery for orbital approaches. J. Craniofac. Surg., 16(6):957-64, 2005.

Erturk, M.; Kayalioglu, G.; Govsa, F.; Varol, T. \& Ozgur, T. The cranioorbital foramen, the groove on the lateral wall of the human orbit, and the orbital branch of the middle meningeal artery. Clin. Anat., 18(1):104, 2005.

Gailloud, P.; Gregg, L. \& San Millán Ruiz, D. Developmental anatomy, angiography, and clinical implications of orbital arterial variations involving the stapedial artery. Neuroimag. Clin. N. Am., 19(2):169-79, 2009.

Georgiou, C. \& Cassell, M. D. The foramen meningo-orbitale and its relationship to the development of the ophthalmic artery. J. Anat., 180(Pt. 1):119-25, 1992. 
MAHAJAN, M. V.; ANUPRIYA, A.; DEVI, G. D.; TANNA, N. A.; MUDIRAJ, NITIN R. \& DAS, S. Clinical implications in orbital and pterional flap surgeries as well as radioimaging studies to determine topographical prevalence and characterization of meningo-orbital foramen in orbits of the indian population. Int. J. Morphol., 38(6):1810-1817, 2020.

Huanmanop, T.; Agthong, S. \& Chentanez, V. Surgical anatomy of fissures and foramina in the orbits of Thai adults. J. Med. Assoc. Thai., 90(11):2383-91, 2007.

Jadhav, S. D.; Roy, P. P.; Ambali, M. P.; Patil, R. J.; Doshi, M. A. \& Desai, R. The foramen meningo-orbital in Indian dry skulls. Natl. J. Integr. Res. Med., 3(4):46-9, 2012

Jovanovic, I.; Ljiljana, V.; Ugrenovic, S.; Dejan, Z.; Vlajkovic, S.; Marija, D. B. \& Vesna, S. Variable foramen of Hyrtl of the human skull. Acta Med. Median., 42(1):1-5, 2003.

Krishnamurthy, A.; Nayak, S. R.; Prabhu, L. V.; Mansur, D. I.; Ramanathan, L.; Madhyastha, S. \& Saralaya, V. The morphology of meningo-orbital foramen in south Indian population. Bratisl. Lek. Listy., 109(11):5179, 2008.

Kwiatkowski, J.; Wysocki, J. \& Nitek, S. The morphology and morphometry of the so-called "meningo-orbital foramen" in humans. Folia Morphol. (Warsz.), 62(4):323-5, 2003.

Lee, H. Y. \& Chung, I. H. Foramen meningo-orbitale and its relationship with the middle meningeal artery. Korean J. Anat., 33(1):99-104, 2000.

Louw, L.; Steyl, J. \& Loggenberg, E. Imaging of unilateral meningoophthalmic artery anomaly in a patient with bilateral nasopharyngeal angiofibroma. J. Clin. Imaging Sci., 4:65, 2014.

Macchi, V.; Regoli, M.; Bracco, S.; Nicoletti, C.; Morra, A.; Porzionato, A.; De Caro, R. \& Bertelli, E. Clinical anatomy of the orbitomeningeal foramina: variational anatomy of the canals connecting the orbit with the cranial cavity. Surg. Radiol. Anat., 38(2):165-77, 2016.

McDermott, M. W.; Durity, F. A.; Rootman, J. \& Woodhurst, W. B. Combined frontotemporal-orbitozygomatic approach for tumors of the sphenoid wing and orbit. Neurosurgery, 26(1):107-16, 1990.

McQueen, C. T.; DiRuggiero, D. C.; Campbell, J. P. \& Shockley, W. W. Orbital osteology: a study of the surgical landmarks. Laryngoscope, 105(8 Pt. 1):783-8, 1995

Mysorekar, V. R. \& Nandedkar, A. N. The groove in the lateral wall of the human orbit. J. Anat., 151:255-7, 1987.

Nabili, S.; Ferguson, A. W.; Gamble, P.; Zealley, I. A. \& MacEwen, C. J. The ophthalmo-meningeal foramen masquerading as an intraocular foreign body. Emerg. Med. J., 23(7):e41, 2006.

O'Brien, A. \& McDonald, S. W. The meningo-orbital foramen in a Scottish population. Clin. Anat., 20(8):880-5, 2007.

Shimada, K.; Kaneko, Y.; Sato, I.; Ezure, H. \& Murakami, G. Classification of the ophthalmic artery that arises from the middle meningeal artery in Japanese adults. Okajimas Folia Anat., 72(2-3):163-76, 1995.

Silva, J.; Araya, C.; Lagos, E.; Salcedo, A. \& Latín, A. Meningo orbital foramen. Int. J. Morphol., 35(2):515-9, 2017.

Simão-Parreira, B.; Cunha-Cabral, D.; Alves, H.; Silva, S. M. \& Andrade, J. P. Morphology and navigational landmarks of the cranio-orbital foramen in a Portuguese population. Ophthalmic Plast. Reconstr. Surg., 35(2):141-7, 2019.

Singh, D.; Dhindsa, G. S.; Singh, S. \& Kaur, J. Morphology and Topographic anatomy of Meningo-orbital foramen in North-Indian Population. Int. J. Adv. Health Sci., 2(2):241-5, 2015.

Tomaszewska, A. \& Zelazniewicz, A. Morphology and morphometry of the meningo-orbital foramen as a result of plastic responses to the ambient temperature and its clinical relevance. J. Craniofac. Surg., 25(3):1033-7, 2014.

\author{
Corresponding author: \\ Nita A. Tanna \\ Department of Anatomy \\ Gmers Medical College And Hospital \\ Gotri Road,Vadodara, Gujarat - 360021 \\ INDIA
}

\section{Email: drmedicalscience39@gmail.com mm1710\&gmail.com}

Received: 26-05-2020

Accepted: 22-07-2020 